\title{
Utero-ovarian arterial blood flow is impaired at 1-month follow-up after robotic-assisted laparoscopic myomectomy
}

\author{
Mahesan AM ${ }^{1 *}$, Sadek $\mathrm{S}^{1}$, Sabouni $\mathrm{R}^{1}$, Paul ABM ${ }^{2}$ and Stadtmauer $\mathrm{L}^{1}$ \\ ${ }^{1}$ The Jones Institute for Reproductive Medicine, Department of ObGyn, Eastern Virginia Medical School, Norfolk, USA \\ ${ }^{2}$ Department of Pathology and Laboratory Medicine, University of Ottawa, Ottawa, Ontario, Canada
}

\begin{abstract}
Background: To determine the effect of robotic-assisted laparoscopic myomectomy (RALM) on utero-ovarian arterial blood flow.

Methods: Preoperative and 1-month postoperative utero-ovarian arterial Color and Spectral Doppler indices were compared in 35 women between the ages of 1845 who underwent RALM for abnormal uterine bleeding and/or infertility. Serum anti-mullerian hormone (AMH) levels were also measured at these time points.

Results: After surgery, there was a statistically significant increase in both pulsatility index, PI ( $p=0.015$ ), and resistance index, RI ( $\mathrm{p}=0.003$ ). Fifteen patients with total fibroid mass $<100 \mathrm{~g}$ had no significant change in blood flow into the ovary after surgery, but 20 patients with fibroid mass $>100 \mathrm{~g}$ had statistically significant increases in PI ( $p=0.013$ ) and RI ( $p=0.010)$. Finally, 19 patients with unilateral fibroids had significant increases in PI ( $p=0.003)$ and RI ( $p=0.003)$ in the utero-ovarian ligament ipsilateral to the fibroids, whereas no significant difference was seen contralateral to the fibroids. AMH decreased after surgery by a mean of 0.66 ( \pm 2.68 ), but this did not reach statistical significance.
\end{abstract}

Conclusions: RALM impaired utero-ovarian arterial blood flow at 1-month postoperative follow-up, shown by an increased resistance of blood flow into the ovary. Further, impairment was associated with total fibroid mass $>100 \mathrm{~g}$. No change in AMH was observed.

\section{Background}

Uterine Fibroids affect $50 \%$ to $80 \%$ of reproductive aged women. They can lead to significant morbidity including menorrhagia, dysmenorrhea, pelvic pain, and infertility [1]. Myomectomy has been the mainstay treatment in women with symptomatic fibroids who wish to retain their reproductive potential [2]. With the advancement of minimally invasive surgery, many cases of intramural and subserosal fibroids are removed by laparoscopic surgery, which may be Roboticassisted [2]. These surgeries have been shown to reduce hospital stay, recovery time, and overall complication rate in comparison to laparotomy [3,4].

Uterine surgery has been associated with compromise in ovarian reserve. In one study, the risk of ovarian failure in women who underwent hysterectomy without bilateral oophorectomy was doubled over those who did not undergo surgery [5]. Another study looking at hysterectomy due to uterine myoma with myomectomy patients as a control group showed that following hysterectomy, ovarian blood supply was decreased as shown by a decreased maximum flow velocity and increased pulsatility index on color Doppler ultrasonography of the ovarian artery at one and three months after surgery [6]. Within their control group of 40 myomectomy patients, the authors looked at peak systolic velocity and pulsatility index of the ovarian artery and found no significant difference after myomectomy. Notably this study noted the myoma volume was $4.22( \pm 0.38) \mathrm{cm}^{3}$, so the fibroid burden was small.

Blood supply to the ovary is from the ovarian vessels as well as from the vessels of the utero-ovarian ligament. Disruption of blood flow to the ovary from the uterus has been associated with decrease in ovarian reserve. In a randomized trial studying the effect of each uterine artery embolization and hysterectomy on ovarian reserve, both interventions were associated with significantly increased FSH, and only UAE was associated with significantly decreased AMH [7]. There was no significant decrease in AMH seen after ovary-sparing hysterectomy.

The impact of blood flow from the uterus to the ovary on ovarian reserve has been demonstrated, however, it is unknown whether this blood flow is compromised following myomectomy. The aim of our study was to quantify changes in utero-ovarian arterial blood flow after robotic-assisted laparoscopic myomectomy (RALM).

\section{Methods}

This was a prospective cohort study of patients undergoing robotic-assisted laparoscopic myomectomy at the Jones Institute for Reproductive Medicine between October 2016 and February 2018. Approval for the study was obtained from the Eastern Virginia Medical School Institutional Review Board.

Included patients were between the ages of 18-45 with regular menstrual cycles who were candidates for laparoscopic approach to myomectomy for symptoms of abnormal menstrual bleeding and/ or infertility. Those with prior adnexal or uterine surgery, suspicion of

${ }^{*}$ Correspondence to: Arnold Mahesan, MD, The Jones Institute for Reproductive Medicine, Department of ObGyn, Eastern Virginia Medical School, 601 Colley Ave., Norfolk, VA 23507, USA, E-mail: mahesaam@evms.edu

Key words: robotic-assisted laparoscopic myomectomy, Doppler ultrasound, ovarian blood flow, ovarian reserve, anti-mullerian hormone

Received: February 12, 2018; Accepted: February 21, 2019; Published: February 25,2019 
malignancy, or use of GnRH agonist within 3 months of surgery were excluded.

3-D ultrasound to map the fibroids and acquire Doppler indices of arterial blood flow in the utero-ovarian ligament, and $\mathrm{AMH}$ measurement, was performed at preoperative visit 1-2 weeks before surgery and 1 month after surgery. A pulsed Doppler range gate was then applied across each vessel $1 \mathrm{~cm}$ from the uterus, ensuring that the angle between the Doppler beam and the vessel was close to 0 degrees. Blood flow velocity waveforms were then obtained and a minimum of three uniform consecutive cardiac cycles were captured (Figure 1). Pulsatility (PI) and resistance indices (RI), end diastolic flow velocity, peak systolic flow velocity, and systolic diastolic ratios were recorded.

RALM was performed using the Da Vinci-SI robot and utilized a three-armed approach. A $2.5 \mathrm{~cm}$ infra-umbilical incision was made into which the Gelpoint Miniport system was placed. The scope and accessory port were introduced at this site through the Gelpoint system. Two $8-\mathrm{mm}$ ports allowing access to the robotic operating arms were placed in the left and the right lower quadrants, both ports were moved cephalad depending on the size of the uterus. The uterine incisions were made with monopolar cautery with efforts made to use blunt dissection with minimal cautery. The incisions were closed with V-Loc 180 polyglyconate unidirectional barbed sutures and continued along two or more layers. The use of single, double or multiple layers to close the uterine incision depended on the depth of the fibroid, with multiple layers on any fibroid that was not superficial. The fibroids were manually morcellated in a bag and retrieved through the $2.5 \mathrm{~cm}$ infraumbilical incision.

Statistical analyses were performed using IBM SPSS (IBM Corp. Armonk, NY). Pre and postoperative variables were compared using Wilcoxon rank-sum test. Categorical variables were compared using chi square test. An alpha level of $<0.05$ was considered statistically significant.

\section{Results}

35 patients were included with mean ages $35.6( \pm 5.4) .74 \%$ were African-American, 20\% Caucausian, and 6\% of another race, and mean BMI was $31.8( \pm 6.4)$. The mean number of fibroids removed was $3.4( \pm$ $2.1)$ and the mean total fibroid specimen weight was $163.4 \mathrm{~g}( \pm 150.0 \mathrm{~g})$ (Table 1).

The PI and RI both increased statistically significantly after surgery (Table 2). There was a mean increase of $1.0( \pm 2.1), \mathrm{p}=0.019$, in the PI, and of $0.21( \pm 0.38), p=0.003$, in the RI. This is consistent with increased resistance to flow into the ovary from the uterus postmyomectomy

A subset analysis was conducted of 19 patients with unilateral fibroids to compare pre and postoperative utero-ovarian arterial flow ipsilateral and contralateral to the fibroids. Statistically significant increases in RI and PI were seen in the ipsilateral utero-ovarian ligament whereas no difference was seen in the contralateral side (Table 3).

Impairment in flow was also associated with total fibroid mass. A subset analysis comparing 15 patients with total fibroid mass $<100 \mathrm{~g}$ vs 20 patients with total fibroid mass $>100 \mathrm{~g}$ revealed no statistically significant changes in flow in the $<100 \mathrm{~g}$ group, but statistically significant increases in mean RI and PI in the $>100$ g group (Table 4).

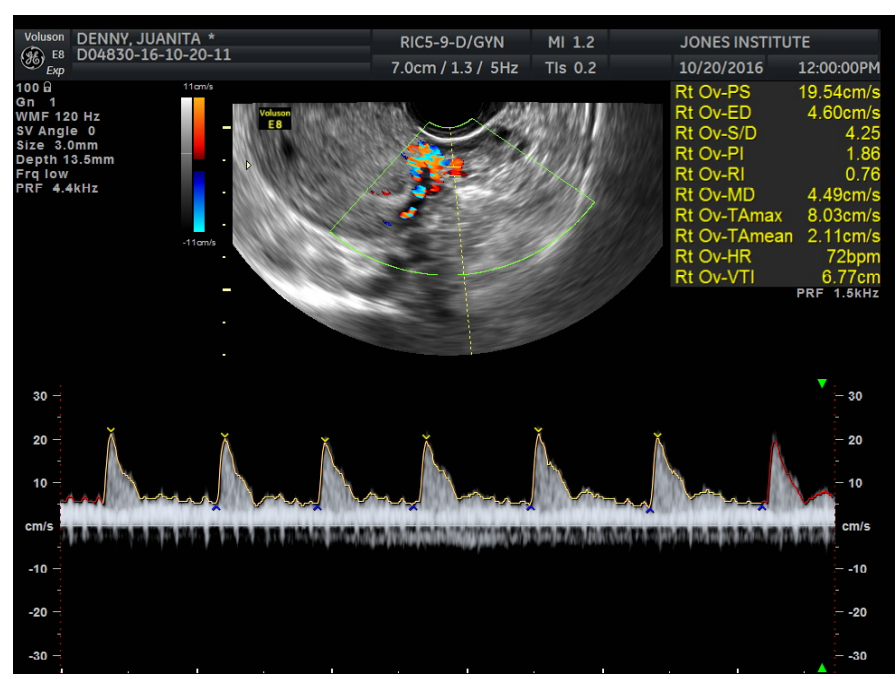

Figure 1. Acquisition of Doppler indices in the Utero-ovarian ligament

Table 1. Population Characteristics of All Patients Undergoing Robotic-Assisted Laparoscopic Myomectomy

\begin{tabular}{|c|c|}
\hline & $\begin{array}{c}\text { Mean }( \pm \mathbf{S D}) \\
\mathbf{n}=\mathbf{3 5}\end{array}$ \\
\hline Age (years) & $35.6(5.4)$ \\
\hline Race & $26(74 \%)$ \\
\hline African-American & $7(20 \%)$ \\
\hline Caucasian & $2(6 \%)$ \\
\hline Other & $31.8(6.4)$ \\
\hline BMI & $3.4(2.1)$ \\
\hline Fibroids Removed $(\mathrm{n})$ & $5.9(1.8)$ \\
\hline Largest Fibroid $(\mathrm{cm})$ & $163.4(150.0)$ \\
\hline Weight of specimen $(\mathrm{g})$ & \\
\hline
\end{tabular}

Table 2. Pre- and Post-Operative Utero-Ovarian Arterial Doppler Measurements

\begin{tabular}{|c|c|c|c|}
\hline & $\begin{array}{c}\text { Pre-op } \\
\text { Mean }( \pm \mathrm{SD}) \\
\mathrm{n}=35\end{array}$ & $\begin{array}{c}\text { Post-op } \\
\text { Mean }( \pm \mathrm{SD}) \\
\mathrm{n}=35\end{array}$ & P-value \\
\hline $\begin{array}{c}\text { Peak Systolic } \\
\text { velocity }(\mathrm{cm} / \mathrm{s})\end{array}$ & $18.8(11.4)$ & $14.7(9.3)$ & 0.18 \\
\hline $\begin{array}{c}\text { End diastolic } \\
\text { velocity }(\mathrm{cm} / \mathrm{s})\end{array}$ & $5.2(4.7)$ & $4.00(2.4)$ & 0.65 \\
\hline S/D Ratio & $3.9(1.8)$ & $5.3(7.5)$ & 0.97 \\
\hline Pulsatility index & $2.1(1.4)$ & $3.1(1.9)$ & 0.019 \\
\hline Resistance index & $0.76(0.19)$ & $0.97(0.33)$ & 0.006 \\
\hline
\end{tabular}

Table 3. Fibroid location Pre- and Post-Operative Utero-Ovarian Arterial Doppler Measurements

\begin{tabular}{|c|c|c|c|c|c|c|}
\hline & \multicolumn{3}{|c|}{ Ipsilateral to fibroid location n=19 } & \multicolumn{3}{|c|}{ Contralateral to fibroid location } \\
$\mathbf{n}=19$
\end{tabular}

Overall, AMH decreased postoperatively by a mean of 0.7 $( \pm 2.7)$, but this difference did not reach statistical significance. Spearman's correlation analysis showed that the AMH difference was not significantly correlated with BMI $(b=-0.28, p=0.19)$, Age $(b=0.12, p=0.59)$, or weight of fibroid specimen removed $(b=-0.10$, $\mathrm{p}=0.65)$. 
Table 4. Total Fibroid specimen $<100 \mathrm{~g} v \mathrm{~s}>100 \mathrm{~g}$ : Pre- and Post-Operative Utero-Ovarian Arterial Doppler Measurements

\begin{tabular}{|c|c|c|c|c|c|c|}
\hline & \multicolumn{3}{|c|}{ Total fibroid specimen $<100 \mathrm{~g}$} & \multicolumn{3}{|c|}{ Total fibroid specimen $>100 \mathrm{~g}$} \\
\hline & $\begin{array}{c}\text { Pre-op } \\
\text { Mean }( \pm \text { SD })\end{array}$ & $\begin{array}{c}\text { Post-op } \\
\text { Mean }( \pm \text { SD })\end{array}$ & P-value & $\begin{array}{c}\text { Pre-op } \\
\text { Mean }( \pm \text { SD })\end{array}$ & $\begin{array}{c}\text { Post-op } \\
\text { Mean }( \pm \text { SD })\end{array}$ & P-value \\
\hline Pulse index & $2.2(0.9)$ & $2.40(1.1)$ & 0.60 & $1.7(1.0)$ & $3.7(2.4)$ & 0.013 \\
\hline Resistance index & $0.82(0.17)$ & $0.89(0.21)$ & 0.40 & $0.70(0.21)$ & $1.08(0.36)$ & 0.010 \\
\hline
\end{tabular}

\section{Discussion}

This study is the first report of the influence of Robotic-assisted Laparoscopic Myomectomy on utero-ovarian blood flow.

In our study, blood flow through the utero-ovarian ligament was significantly impaired at the 1 month follow up. Further, when myomectomy was performed on only one side of the uterus, the uteroovarian blood flow was significantly impaired only on that side. This suggested that the impairment could be related to surgical vascular disruption, since the un-operated side did not show a postoperative impairment in flow.

The weakness of the study was the small sample size and the lack of association of the scans with the phase of the menstrual cycle. However, the patient acted as her own control between pre- and post-operative measurements. Further, in cases where fibroids were unilateral, the unoperated side acted as a control to the operated side. Care was taken to minimize variability in the scanning technique by following the same protocol of measuring the blood flow at the same place on the vessel (1 $\mathrm{cm}$ from the ovary) and the 2 physicians performing the scan worked together in pairs to have consistent measurements with low interobserver and intraobserver variability.

The studies following Doppler parameters of ovarian arterial blood flow after uterine surgery are still limited and controversial [8-11]. Xiangying et al. showed hysterectomy was associated with a decrease in ovarian reserve measured by FSH, with a decrease in ovarian blood flow measured by Vmax and pulsatility index of the ovarian artery at 1 and 3 months follow up [5,6]. However, in contrast Lee et al. [12] showed that 3 months after hysterectomy there was no notable change in ovarian Doppler blood flow or measure of ovarian reserve. Hysterectomy with ovarian preservation has also been associated with long-term consequences to ovarian function. Moorman et al. [9] showed hysterectomy is associated with a nearly two-fold increased risk of ovarian failure.

We found a correlation between total fibroid specimen weight and magnitude of decrease in utero-ovarian ligament arterial blood flow. Farmakides et al demonstrated that there is a positive correlation between fibroid uterus size and vascular supply [10]. Our observation of no significant impact on utero-ovarian arterial blood flow with total fibroid weight $<100$ grams may be due to surgery on smaller fibroids having less impact on vascular supply. This hypothesis suggests less flow impairment may occur if fibroids are reduced in size using medical therapy prior to surgery, and deserves further investigation.

$\mathrm{AMH}$ has been reported as a marker for ovarian reserve $[11,13]$. Our study found no significant change in AMH after RALM although there is a trend towards decrease in AMH immediately post-operative. This is consistent with the work of Cela et al. [2] who studied the effect of RALM on ovarian reserve measuring AMH, FSH and antral follicle count (AFC) and reported no significant change in these parameters. In addition, longer follow-may show a further correction of any AMH changes and may also show correction of the increased ovarian resistance to blood flow post-myomectomy in the larger fibroid uteruses.

\section{Conclusion}

Our data showed significant increases in pulsatility and resistance indices in utero-ovarian ligament arteries following robotic myomectomy. Whether this insult could predispose to long-term consequences to ovarian function or response to fertility medications is unknown. Further study is warranted to evaluate if the observed impairment in utero-ovarian blood flow persists in the longer term, or if there are any future clinical consequences.

\section{Declarations}

\section{Ethics approval and consent to participate}

Approval for the study was obtained from the Eastern Virginia Medical School Institutional Review Board

\section{Consent for publication}

Not applicable

\section{Availability of data and material}

Dataset attached as supplemental data

\section{Competing interests}

None

\section{Funding}

None

\section{Authors' contributions}

AM Mahesan: Protocol/project development, Data collection or management, Data analysis, Manuscript writing/editing

S Sadek: Data collection or management, Data analysis, Manuscript writing/editing

R Sabouni: Data collection or management

ABM Paul: Data collection or management, Data analysis

L Stadtmauer: Protocol/project development, Data collection or management, Data analysis, Manuscript writing/editing

All authors read and approved the final manuscript

\section{Acknowledgements}

\section{None}

\section{References}

1. Borah BJ, Nicholson WK, Bradley L, Stewart EA (2013) The impact of uterine leiomyomas: A national survey of affected women. Am J Obstet Gynecol 209. [Crossref]

2. Cela V, Freschi L, Simi G, Tana R, Russo N, et al. (2013) Fertility and endocrine outcome after robot- assisted laparoscopic myomectomy (RALM). Gynecol Endocrinol 29: 79-82. [Crossref]

3. Advincula AP, Xu X, Goudeau IV S, Ransom SB (2007) Robot-assisted laparoscopic myomectomy versus abdominal myomectomy: A comparison of short-term surgical outcomes and immediate costs. J Minim Invasive Gynecol 14: 698-705. [Crossref] 
4. Sizzi O, Rossetti A, Malzoni M, Minelli L, La Grotta F, et al. (2007) Italian multicenter study on complications of laparoscopic myomectomy. J Minim Invasive Gynecol 14: 453-462. [Crossref]

5. Moorman PG, Myers ER, Schildkraut JM (2011) Effect of hysterectomy with ovarian preservation on ovarian function. Obstet Gynecol 118: 1271-1279. [Crossref]

6. Xiangying H, Lili H, Yifu S (2006) The effect of hysterectomy on ovarian blood supply and endocrine function. Climacteric 9: 283-289. [Crossref]

7. Hehenkamp WJ1, Volkers NA, Broekmans FJ, de Jong FH, Themmen AP (2007) Loss of ovarian reserve after uterine artery embolization: a randomised comparison with hysterectomy. Hum Reprod 22: 1996-2005. [Crossref]

8. Petri Nahás EA, Pontes A, Nahas-Neto J, Borges VTM, Dias R, et al. (2005) Effect of total abdominal hysterectomy on ovarian blood supply in women of reproductive age. J Ultrasound Med 24:169-174. [Crossref]
9. Lee D, Kim NY, Kim MJ, Yoon B, Choi D, et al. (2011) Effects of laparoscopic surgery on serum anti- müllerian hormone levels in reproductive-aged women with endometrioma. Gynecol Endocrinol 27: 733-736. [Crossref]

10. Farmakides G, Stefanidis K, Paschopoulos M, Mamopoulos M, Lolis D (1998) Uterine artery Doppler velocimetry with leiomyomas. Arch Gynecol Obstet 262: 53-57. [Crossref]

11. Van Rooij IAJ, Broekmans FJM, Te Velde ER, Fauser BCJM, Bancsi LFJMM, et al (2002) Serum anti-Müllerian hormone levels: A novel measure of ovarian reserve. Hum Reprod 17: 3065-3071. [Crossref]

12. Lee DY, Park HJ, Kim BG, Bae DS, Yoon BK, et al. (2010) Change in the ovarian environment after hysterectomy as assessed by ovarian arterial blood flow indices and serum anti-Müllerian hormone levels. Eur J Obstet Gynecol Reprod Biol 151: 82-85. [Crossref]

13. De Vet A, Laven JSE, De Jong FH, Themmen APN, Fauser BCJM (2002) Antimüllerian hormone serum levels: A putative marker for ovarian aging. Fertil Steril 77: 357-362. [Crossref]

Copyright: (C2019 Mahesan AM. This is an open-access article distributed under the terms of the Creative Commons Attribution License, which permits unrestricted use, distribution, and reproduction in any medium, provided the original author and source are credited. 